\title{
EL SEPULCRO DE LA INFANTA DOÑA LEONOR, HIJA DE ALFONSO X EL SABIO, EN EL REAL MONASTERIO DE SANTO DOMINGO DE CALERUEGA (BURGOS)*
}

Data recepción: 2013/10/26

Data aceptación: 2014/05/19

Fernando Gutiérrez Baños

Contacto autor: fbanos@fyl.uva.es

Universidad de Valladolid

RESUMEN

La infanta doña Leonor, una de las hijas del rey de Castilla Alfonso X el Sabio, murió en 1275 mientras acompañaba a su padre a la "ida al imperio". Alfonso X ordenó que fuese enterrada en el Real Monasterio de Santo Domingo de Caleruega (Burgos). Este convento había sido fundado recientemente por el monarca para honrar el lugar de nacimiento de Santo Domingo de Guzmán, el fundador de la orden de predicadores, vinculando, de esta manera, el prestigio del santo y de su orden a sus propias aspiraciones políticas y familiares. Hoy en día solo subsisten unos pocos restos de este enterramiento, pero, aun así, son un importante testimonio del arte alfonsí. En este artículo se estudia a fondo el sepulcro de la infanta doña Leonor en el contexto del arte funerario y cortesano del periodo subrayando la forma en que expresa una afición por una estética basada en las telas, en la heráldica y en la tradición andalusí que resulta singular en el contexto del arte cortesano europeo del siglo XIII.

Palabras clave: pintura gótica, heráldica, sepulcro, Alfonso X, Caleruega

ABSTRACT

The daughter of Alfonso X "The Wise", King of Castile, the Infanta Leonor died in 1275 while accompanying her father to a meeting of great importance with Pope Gregory X. Alfonso X ordered that she should be buried at the Real Monasterio de Santo Domingo in Caleruega, Burgos, which he had recently founded in honour of the birthplace of St Dominic, the founder of the Dominican order. In stipulating her burial there, he established a link between his familial and political aspirations and the prestige of the saint and the order. Though little of the tomb has survived to this day, the remains are nevertheless an important example of the art of the Alfonsine era. This article analyses the tomb in the context of the courtly and funerary art of the period, and highlights the way in which it expresses a fondness for an aesthetic based upon textiles, heraldry and the Andalusian tradition, which is highly unique in terms of European courtly art of the thirteenth century.

Keywords: Gothic painting, heraldry, tomb, Alfonso X, Caleruega

Entre la descendencia legítima de Alfonso $X$ el Sabio se cuenta una infanta de nombre Leonor que no ha sido demasiado bien tratada por la historiografía. La Crónica de Alfonso X, a la que, como es bien sabido, dio forma a finales del reinado de Alfonso XI Fernán Sánchez de Valladolid, nos brinda un relato parcial, partidista y erróneo, a menudo, en los detalles del reinado del rey Sabio en el que nuestra infanta comparece en una única ocasión cuando se hace el recuento de la descendencia del monarca: et otra que dixieron donna Leonor que casó en Murçia con el marqués [de Monferrand]'. En realidad, la infanta que casó en Murcia en 1271 con Guillermo VII, marqués de Monferrato, no fue doña Leonor, sino su hermana doña Beatriz ${ }^{2}$. Las Memorias históricas del rey don Alonso el Sabio que recopilara a finales del siglo XVII el marqués de Mondéjar, publicadas póstumamente en 1777, marran, asimismo, al referirse 
a nuestra infanta, pues, a pesar de que se las considera, con justicia, el punto de partida de la moderna historiografía crítica sobre el gran monarca castellano, presentan a doña Leonor, a la que creen la menor de las hijas del rey Sabio, como esposa de don Diego López de $\mathrm{Haro}^{3}$. En realidad, la infanta que casó en 1282 con este magnate que acabaría convirtiéndose en señor de Vizcaya no fue doña Leonor, sino su hermana doña Violante (la menor, en efecto, de las hijas del rey Sabio $)^{4}$.

Así pues, ni marquesa de Monferrato ni señora de Vizcaya, si bien la antigüedad y la autoridad de las fuentes que así la presentaron han contribuido a desdibujar un tanto su figura. Las noticias ciertas sobre la infanta doña Leonor deben buscarse en las fuentes de su época. Ballesteros Beretta reconoció su rastro en la documentación del repartimiento de Murcia, en la que se menciona a Juan del Corral, amo del inffante donna Helyonor, y a Juan Domínguez, criado de la inffante donna Leonor ${ }^{5}$. Ballesteros Beretta pensó, asimismo, que, o bien ella, o bien su hermana la infanta doña Violante, anteriormente mencionada, pudieron ser ofrecidas en matrimonio a Tomás de Saboya como parte del juego de alianzas que Alfonso $X$ estaba tejiendo a la altura de 1271 en el marco de sus aspiraciones imperiales ${ }^{6}$. Las noticias más ciertas sobre esta desgraciada infanta se refieren a su muerte, acontecida en el transcurso del regreso de la "ida al imperio" en aquel particular annus horribilis de Alfonso X que fue el de 1275: entonces no tendría ni siquiera veinte años (González Jiménez sitúa su nacimiento ca. 1256) ${ }^{7}$. No me consta que se cerrara acuerdo matrimonial alguno para ella.

Desgraciada, incluso, en la muerte, el cúmulo de desastres que tuvieron lugar en aquel año (en el que se disputan la primacía la imposición de la definitiva renuncia de Alfonso $X$ a sus aspiraciones imperiales tras su entrevista con el papa Gregorio X en Belcaire y la muerte del infante don Fernando de la Cerda, heredero de la corona) han ensombrecido su deceso, puntualmente registrado en una de las crónicas catalanas que nos ofrecen un relato vivo y colorista de la "ida al imperio" y en dos cronicones castellanos, testimonios todos ellos de finales del siglo XIII. La crónica de Bernat Desclot dice: $E$ en aquel viatge, mentre s'en tornava a Barçelona, murí i seu nabot, fil d'En Manuel son frare, e $i^{a}$ sua fila, molt bela donçela, qui avia nom dona Lionor (capítulo LXVI) ${ }^{8}$. Los Anales Toledanos III dicen: Anno Domini $M^{\circ} C C^{\circ} L X X^{\circ} V^{\circ}(.$.$) in regresu aput$ Montem Pesulanum decessit Alfonsus Emanuelis nepos eius et filius domini Emanuelis fratris Regis et domna Elianor filia Regis mortua est in uia in regresu (§ 59) ${ }^{9}$. Los que cabría denominar, acaso, Anales Silenses dicen: Era de mill e trezientos e treze años (...) E él seyendo en Balcayre murió allá la ynfanta doña Leonor, su fija, e mandóla llevar a enterrar a Caleruega (§ 6) ${ }^{10}$.

Las tres fuentes coinciden en situar la muerte de la infanta doña Leonor en el año 1275 en el contexto de la "ida al imperio", pero difieren en pequeños matices. La "ida al imperio" (el viaje de Alfonso $X$ a Belcaire para resolver, definitivamente, sus aspiraciones al trono imperial) fue un auténtico reto logístico y diplomático, expresión, en sí mismo, de las altas aspiraciones del soberano, que, acompañado de su corte y de una guarnición acorde con su condición, emprendió el camino desde Alicante en octubre de 1274 atravesando de sur a norte toda la Corona de Aragón ${ }^{11}$. Parte del séquito, incluyendo a la reina y a sus hijos (entre los cuales se encontraría, sin duda, la infanta doña Leonor), se quedó en Perpiñán mientras Alfonso $X$ se adentraba en Francia para llegar, finalmente, a Belcaire, donde permaneció entrevistándose infructuosamente con el papa entre principios de mayo y principios de agosto. Los Anales Silenses colocan la muerte de la infanta doña Leonor en el tiempo en que su padre permaneció en Belcaire: $E$ él seyendo en Balcayre... Los Anales Toledanos III, en cambio, señalan su muerte durante el viaje de regreso (in uia in regresu), en lo que parece coincidir Bernat Desclot (en aquel viatge, mentre s'en tornava a Barçelona...). De regreso, Alfonso $X$ enfermó gravemente en Montpellier $\mathrm{y}$, tras recoger a su familia en Perpiñán, continuó atravesando Cataluña para encaminarse a Castilla cuanto antes. La mayor parte de los historiadores ubica la muerte de la infanta doña Leonor una vez emprendido el camino desde Perpiñán, quizás, como quiere Ballesteros Beretta, a finales del mes de septiembre ${ }^{12}$. 
Si para una noticia lejana como los detalles acerca del fallecimiento de la infanta doña Leonor el cronicón silense pudo pecar de imprecisión, para una noticia cercana como su enterramiento, por voluntad paterna (mandóla llevar a enterrar...), en Caleruega debemos darle el máximo crédito, pues los Anales Silenses manifiestan un conocimiento preciso de las circunstancias de su territorio circundante a finales del siglo XIII. Los Anales Silenses son, además, la única fuente antigua que menciona el enterramiento de la infanta, coincidiendo con ellos la tradición de la casa que continúa albergando sus restos: el Real Monasterio de Santo Domingo de Caleruega, creado por Alfonso X en esta localidad castellana del obispado de Osma con la intención de honrar el solar de Santo Domingo de Guzmán, fundador de la orden de predicadores. De hecho, desde principios del siglo XX distintas publicaciones sobre este cenobio se han hecho eco de la presencia entre sus muros del sepulcro de la infanta ${ }^{13}$, la cual consta no solo por los Anales Silenses, tantas veces citados, sino también por al menos dos documentos antiguos originales que se conservan en el archivo conventual ${ }^{14}$. Sin embargo, el carácter local y extraordinariamente circunscrito de muchas de las publicaciones que se han ocupado de este sepulcro, en conjunción con la tardía edición de los Anales Silenses, ha oscurecido el conocimiento de este enterramiento, arrojando, con ello, una vez más, la sombra de la confusión, más terrible, si cabe, que la sombra del olvido, sobre la memoria de la infanta. En su clásico Sepulcros de la casa real de Castilla de 1954, Ricardo del Arco, desorientado por los errores del marqués de Mondéjar, ignora por completo el sepulcro de Caleruega, aferrándose, a cambio, a las erráticas noticias que sobre la presencia del sepulcro de la infanta doña Leonor en la iglesia parroquial de Miedes de Aragón (Zaragoza) se hicieron llegar a la Real Academia de la Historia a principios del siglo $\mathrm{XIX}^{15}$.

Maltratado por el tiempo en no menor medida que la memoria de su titular, el sepulcro de Caleruega, pese a su condición fragmentaria, es un importante ejemplo de sepulcro regio de la era alfonsí que merece ser analizado en su contexto poniendo de relieve su relación con otras realizaciones funerarias del momento.

\section{El Real Monasterio de Santo Domingo de Caleruega: una empresa Alfonsí}

El Real Monasterio de Santo Domingo de Caleruega cuenta con magníficos estudios históricos, elaborados tanto desde la perspectiva conventual ${ }^{16}$ como desde la perspectiva académica ${ }^{17}$. Cuenta, asimismo, con buenas aproximaciones a su patrimonio artístico ${ }^{18}$, que, a pesar de las grandes reformas de que fue objeto el cenobio en el siglo XVIII, mantiene muchos elementos de época medieval. Su carácter alfonsí no es, en absoluto, desconocido. Sin embargo, apenas es tenido en cuenta cuando se trata de analizar el mecenazgo artístico del rey Sabio.

Cuando Santo Domingo de Guzmán fue canonizado en 1234, su hermano fray Manés de Guzmán se desplazó a Caleruega e instó a sus gentes a edificar una iglesia a él dedicada sobre el lugar de nacimiento del recién proclamado santo $^{19}$. Transcurridos algunos años, Alfonso $X$ decidió dar más relieve al solar del fundador de la orden dominicana disponiendo la creación, junto a la iglesia de Santo Domingo, de un convento de religiosas de su orden, trasladando, para ello, a la comunidad del convento de Santa María de Castro de San Esteban de Gormaz, que se remontaba, acaso, al siglo XII y que se había incorporado a la nueva congregación ${ }^{20}$. Los hitos que marcan el desarrollo de esta fundación son bien conocidos: 1.- 31 de enero de 1266, don Agustín, obispo de Osma, pone, por orden del monarca, la primera piedra del nuevo complejo monástico; 2.- 4 de junio de 1266, desde Sevilla, Alfonso $X$ dona a la comunidad el señorío de Caleruega, que él mismo se ha ocupado de reorganizar; 3.- 31 de octubre de 1266, doña Toda Martínez, priora de la comunidad entre 1256 y 1276, toma posesión del señorío de Caleruega; 4.- 11 de julio de 1270, Alfonso X en persona entrega a la priora la Eglesia que es alli o santo Domingo nascio (lo que marcaría el traslado de la comunidad desde San Esteban de Gormaz a Caleruega); 5.- 8 de noviembre de 1277, desde Burgos, el infante don Sancho se compromete a acabar el monasterio de acuerdo con los deseos de su padre:

si alguna cosa aviniere de vos, lo que dios no quiera, ante que el monesterio que vos fazedes de 
Santo Domingo de Caleruega fuesse acabado que yo que lo cumpla e que lo acabe assi como deve seer tan bien la eglesia como todo lo al que y fuere mester fasta que sea todo acabado assi como vos lo ordenastes e tuviestes por bien que se fiziesse ${ }^{21}$

Ríos de la Llave piensa que las obras estarían concluidas en 1279 o, como muy tarde, en $1284^{22}$.

Del conjunto monástico medieval, al que el Cerratense, que lo conoció, se refiere como obra realizada iuxta magnificenciam principalem ${ }^{23}$, subsiste parte de la iglesia, a la que se suele denominar "iglesia de Alfonso X" 24 , de elegante, aunque no especialmente atrevida, arquitectura gótica, puesta bajo la advocación de Santa María. Esta iglesia quedó finalmente convertida en coro de la actual iglesia conventual, configurada cuando, a partir de finales del siglo XVI, se reedificó por completo la cercana iglesia de Santo Domingo, que se encontraba, exenta, al este de la iglesia de Santa María, uniéndola a esta (la nueva construcción se convirtió en presbiterio de la iglesia conventual definitivamente configurada) ${ }^{25}$. Subsisten, asimismo, aunque muy alterados por reformas dieciochescas y por restauraciones modernas, el claustro y salones circundantes (estos totalmente desfigurados), de arcaizante arquitectura en sus galerías, que no deben de ser anteriores al siglo XV.

Como ha subrayado Aguadé Nieto, Alfonso $\mathrm{X}$ el Sabio, al emprender con tanto empeño esta fundación, pretendió, en cierta manera, apropiarse de la figura de Santo Domingo de Guzmán, prestigioso santo castellano de reciente canonización, para exaltación tanto del reino de Castilla como de su propio linaje, contribuyendo, de esta manera, a la afirmación, con un cierto afán nacionalista, de la preeminencia castellana ${ }^{26}$. Sus intenciones quedan patentes en el privilegio rodado de 4 de junio de 1266 por el que el monarca dona el señorío de Caleruega a la nueva comunidad, más o menos parafraseado en documentos posteriores:

Connosciendo la grand piedat que el [Dios] ovo a Espanna e sennaladamiente al Regno de Castiella en querer que nasciesse y e fuesse ende natural el bienaventurado santo Domingo que fué Padre e fazedor de la Orden de los frayres Predicadores por quien nuestro sennor Jehsuchris- to mostro muchos e maravillosos miraglos en el mundo. Nos cobdiciando fazer algun servicio que a Dios ploguiesse. E otrossi por que reçibiesse alguna onra este bienaventurado santo en nuestro sennorio e sennaladamiente en aquel logar o el nascio que ha nombre Caleruega, fazemos y Monasterio de duennas de su orden misma que sirvan a Dios en el e a este santo glorioso e que rueguen a Dios sennaladamiente por las almas del muy noble Rey don Fernando nuestro Padre e de la muy noble Reyna donna Beatriz nuestra madre e por los otros Reyes onde nos venimos e otrossi que rueguen por nos e por la Reyna mi mugier e por nuestros ffijos e por los otros de nuestro linage que de nos vernan ${ }^{27}$.

Caleruega no fue, pues, una fundación piadosa, sin más, sino una fundación dotada de un alto contenido político y propagandístico. Por ello es por lo que, aunque Alfonso $X$ nunca tuviese la intención de hacer de su real monasterio un panteón regio ${ }^{28}$, enfrentado en 1275 a la penosa necesidad de dar sepultura a dos de sus hijos, destinó a uno de ellos a esta casa para hacer tristemente efectivo de manera inmediata su deseo de que las monjas rueguen por nos e por la Reyna mi mugier e por nuestros ffijos e por los otros de nuestro linage que de nos vernan. Por su posición dinástica, el cuerpo de Fernando de la Cerda hubo de ser enterrado en el que se había convertido en centro ceremonial de la monarquía castellana (esto es, en el monasterio cisterciense de Santa María la Real de las Huelgas de Burgos), pero el cuerpo de la joven Leonor se usó para sancionar, como si de un sello se tratase, el compromiso del monarca con su fundación calerogana.

\section{El sepulcro de la infanta doña Leonor: historia material}

Hoy el sepulcro de la infanta doña Leonor no es más que una ruina miserable que las religiosas establecidas por su padre intentan conservar con el mayor decoro posible (Fig. 1) ${ }^{29}$. Expuesto durante algún tiempo en la zona que los visitantes podían recorrer, su pobre condición aconsejó hace algunos años retirarlo a una zona discreta de la clausura. Hoy no es más que una vulgar caja de madera que encierra en su interior una urna de metal que alberga los restos de la infan$\mathrm{ta}^{30}$. La caja de madera presenta, en su frente, sobrepuesto a su estructura, parte de un tablón 


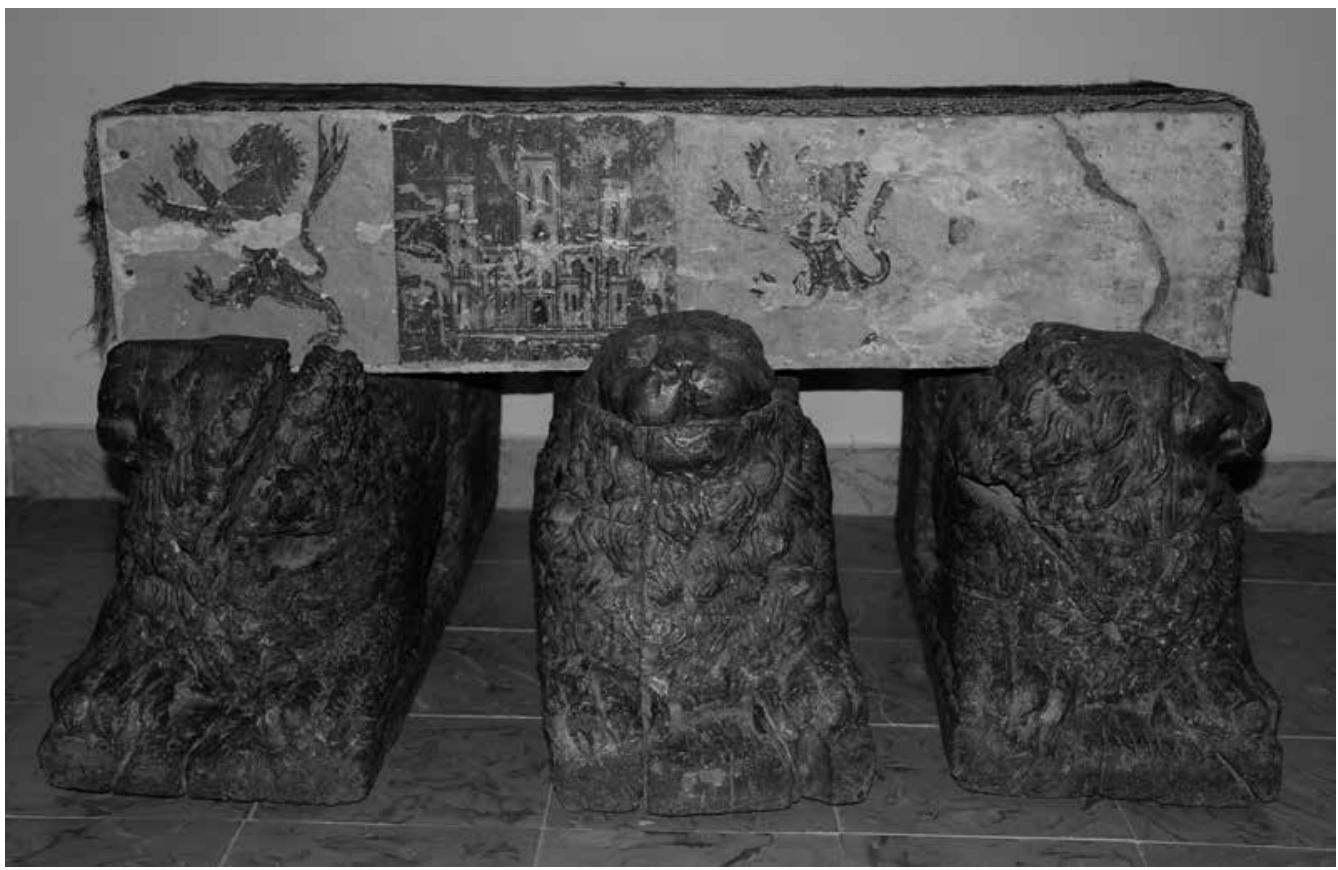

Fig. 1. Sepulcro de la infanta doña Leonor en el Real Monasterio de Santo Domingo de Caleruega. Estado en 2013.

del sepulcro original. Este, de madera distinta (más antigua y carcomida), mide $25 \times 111 \mathrm{~cm}$ y presenta una decoración pictórica sobre pergamino aplicado a la madera que muestra, alternativamente, las señales de Castilla y de León comenzando por León. El conjunto se asienta sobre los tres leones de madera que en origen sustentarían el sepulcro, que hoy se antojan excesivos para tan reducido reducto ${ }^{31}$.

La referencia más antigua al sepulcro que nos es dado conocer se encuentra en el informe sobre el estado general del monasterio elaborado entre 1736 y 1739 por el arquitecto arandino José de las Cosigas a instancias del maestro general de la orden fray Tomás de Ripoll ${ }^{32}$. De las Cosigas dice así hablando del coro: “(...) reconozió a la entrada del coro, que corresponde y está en la galería de la parte de el mediodía, un artesonado soberano que incluie mucha grandeza, así por lo precioso de su fábrica como por lo costoso de ella, que su ejecución costaría más de veinte mill ducados. Tiene de longitud dicha pieza setenta y tres pies y de ancho veinte y seis, en donde se halla, en una esquina, un sepulcro, manteniéndole tres leones de bastante magni- tud, y en la cubierta, fachadas y costados, tiene pintados treinta y seis leones con otros tantos castillos en forma de escudos, que son armas reales de Castilla, en donde está depositado el cuerpo de una hija de el rei don Alonso el Sabio, fundador de este real convento, según resulta de instrumentos que paran en su archibo". En 1757 un manuscrito silense menciona, de nuevo, el sepulcro, atribuyéndolo a doña Margarita de la Cerda o de Lara (hija de don Fernando de la Cerda, hijo, a su vez, del infante del mismo nombre -bisnieta, por tanto, de Alfonso X el Sabio-), quien, según don Pedro López de Ayala, murió monja en Caleruega ${ }^{33}$ : "Y se supone que su cuerpo es el que está en el salón antechoro, en su tumba cubierta de un paño con las armas reales de aquel tiempo"34. Estas descripciones nos presentan el sepulcro como un gran sarcófago recubierto, en su integridad, por emblemas heráldicos (nada menos que setenta y dos cuarteles frente a los apenas cuatro cuarteles que subsisten en la actualidad), que, asentado sobre tres leones (sin duda, los tres leones que todavía se conservan), se encuentra a la entrada del coro de la comunidad, muy probablemente, a la 
sazón, el coro original del edificio alfonsí, que, según sor Carmen González, se extendía, como prolongación directa de la iglesia, por buena parte de la crujía meridional del claustro ${ }^{35}$. Sin duda fue este su emplazamiento original, como ponen de manifiesto ejemplos más o menos contemporáneos en los que los sepulcros de los fundadores de comunidades monásticas (y considero que en este grupo podemos incluir el sepulcro de la infanta doña Leonor, en el que Alfonso $X$ actuaría por cuerpo interpuesto) se disponen en esta ubicación para hacer factible de la manera más literal posible el deseo de que las monjas rueguen por nos común a todas estas iniciativas ${ }^{36}$. Sirvan como referencia los sepulcros en contextos mendicantes de la infanta doña Berenguela, hermana de la infanta doña Leonor, en el coro del convento de Santa Clara de Toro ${ }^{37}$ o de doña Teresa Gil en el coro del convento de Sancti Spiritus de Toro, por no insistir en el ejemplo más cercano y más prestigioso, aunque también más controvertido, representado por los sepulcros de Alfonso VIII y de su esposa la reina doña Leonor de Inglaterra en el coro del monasterio cisterciense de Santa María la Real de las Huelgas de Burgos ${ }^{38}$. Debemos evaluar, no obstante, si a la altura del siglo XVIII el sepulcro de la infanta doña Leonor se encontraba en su disposición original: De las Cosigas nos lo presenta "en una esquina". Es posible que, dadas las características de los leones que lo sustentaban, se dispusiera ya en origen arrimado a la pared (si bien estaría pintado por sus cuatro costados), pero, con más frecuencia, este tipo de sepulcros se colocaba en el centro del coro.

Las siguientes referencias al sepulcro lo ubican en el capítulo o cementerio de la comunidad. En 1931 el P. Martínez lo describía como "una urna grande de madera pintada con leones y castillos" que se encontraba "En el lugar de enterramiento de las religiosas de Caleruega" (poco antes el P. Peláez lo describía como "una grande urna o arca, forrada exteriormente de una tela metálica decorada con leones y casti"los", sin precisar su ubicación) ${ }^{39}$. La dependencia denominada capítulo o cementerio de la comunidad, situada en el ángulo SE del claustro, con acceso tanto desde el claustro como desde el inmediato coro, se encuentra, en la actualidad, deshecha, habiendo cedido su espacio a una serie de habitaciones que se usan como despacho y como locutorios. Esta dependencia se fabricó en 1793, una vez desmantelado el primitivo lugar de enterramiento de las monjas en el antiguo coro del monasterio en el contexto de las grandes obras de reforma que se iniciaron en 1770 a instancias del maestro general fray Juan Tomás de Boixadors ${ }^{40}$. Debió de ser entonces cuando el sepulcro de la infanta doña Leonor abandonó para siempre su emplazamiento original. A principios del siglo XX era frecuente que se abriese para mostrar los restos momificados de la infanta ${ }^{41}$. Esto nos permite saber que el esqueleto de doña Leonor se encontraba "perfectamente trabado, indicando la corpulencia casi varonil y estatura elevada de esta infanta" (como corresponde a una mujer que frisaba la veintena $)^{42}$ o que "Su vestido era de raso azul celeste, gola bien conservada en sus formas" 43 .

Poco después de que se ocupara de él el P. Martínez el sepulcro fue movido para preparar un nuevo enterramiento, produciéndose, entonces, el desastre: los restos de doña Leonor se hicieron polvo, "escepto alguna parte del vestido", y, ya desarticulados, se decidió trasladarlos a una urna más pequeña para cuya fabricación se aprovechó parte del frontal de la urna antigua ${ }^{44}$. El traslado se efectuó el 24 de noviembre de $1933^{45}$. El nuevo sepulcro conoció distintas ubicaciones. Durante un tiempo estuvo colocado frente a la entrada del cementerio, sobre unos pies de hierro, hasta que en 1975 se trasladó al claustro, a la crujía del museo en ese momento recién habilitado, instalándose, entonces, de nuevo, sobre los tres leones del sepulcro original, ahora de grotesca apariencia hipertrofiada ${ }^{46}$. Su pobre condición aconsejó, finalmente, retirarlo.

\section{El sepulcro en su contexto}

El sepulcro de la infanta doña Leonor, tal y como nos es dado conocerlo no solo por los testimonios de quienes lo vieron en su estado original, sino también por los girones que del mismo nos han llegado, hermana con toda una serie de obras producidas contemporáneamente en el entorno cortesano, con proyección, más allá de este reducido círculo, en el entorno burgalés ${ }^{47}$. Debió de ser fabricado no mucho tiempo después de la muerte de la joven, una vez que la 
corte, finiquitada su desastrosa "ida al imperio", regresó a Castilla, coincidiendo con el momento en que las obras del Real Monasterio de Santo Domingo de Caleruega caminaban hacia su culminación ${ }^{48}$. Su estrecha relación con el sepulcro de su hermano el infante don Fernando de la Cerda (Fig. 2) y con otros sepulcros del cenobio burgalés de las Huelgas así parece avalarlo ${ }^{49}$.

En efecto, el sepulcro de la infanta doña Leonor consistía en un gran sarcófago asentado sobre tres leones que presentaba sus distintas superficies recubiertas mediante una decoración pictórica de carácter heráldico evocadora de los tejidos característicos de un boato regio que había hecho de las decoraciones emblemáticas su elemento más significativo ${ }^{50}$. Esta decoración pictórica pretendía ser el trasunto de la costumbre de cubrir los enterramientos con ricos paños ${ }^{51}$. El modelo textil adoptado en la decoración del sepulcro de la infanta doña Leonor es mucho más sencillo que el modelo textil adoptado en la decoración del sepulcro de su hermano el infante don Fernando de la Cerda, pues se limita a la reiteración de las señales de Castilla y

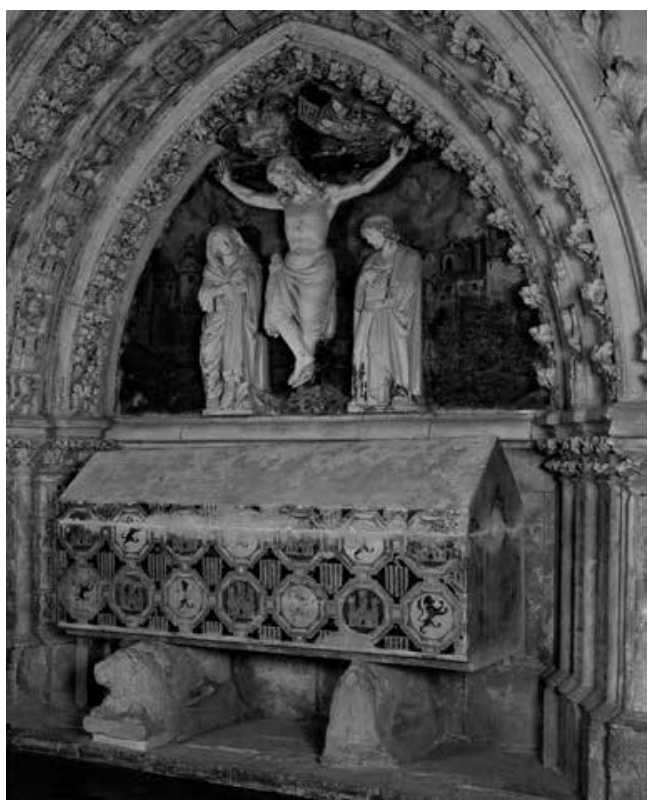

Fig. 2. Sepulcro del infante don Fernando de la Cerda en el monasterio cisterciense de Santa María la Real de las Huelgas de Burgos (foto: Vestiduras ricas. El monasterio de las Huelgas y su época 1170-1340 (catálogo de exposición), Patrimonio Nacional, Madrid, 2005, p. 66). de León en cuarteles cuadrangulares. Tejidos de estas características aparecen representados en el Códice Rico de las Cantigas de Santa María ${ }^{52}$, conservándose, excepcionalmente, fragmentos de un tejido así (Fig. 3, a saber, el empleado para la confección del manto de Fernando III, que, procedente de la capilla real de Sevilla, pertenece, en su porción más significativa, a la Real Armería de Madrid) ${ }^{53}$. Poco antes de que se fabricara el sepulcro de la infanta doña Leonor telas de estas características habían sido fijadas perennemente a los muros de manera ficticia con la mediación de la pintura en las bóvedas de los tramos séptimo y octavo de la nave de San Juan Evangelista del monasterio cisterciense de Santa María la Real de las Huelgas de Bur$\operatorname{gos}^{54}$ y con la mediación de la escultura en la portada del claustro de la catedral de Burgos ${ }^{55}$. Contemporáneamente un diseño similar era perpetuado con la mediación de la plata repujada en el mobiliario de la capilla real de la catedral de Sevilla, del que subsisten algunos elementos $^{56}$. El prestigio de estas obras haría que poco después se adoptase el mismo patrón, más allá del ámbito estrictamente cortesano, en la decoración del muro oriental de la ermita de San Andrés de Mahamud, promovida por el prócer don Sancho Sánchez Carrillo ${ }^{57}$. Todas estas obras son características de una estética cortesana estudiada por Sánchez Ameijeiras que toma carta de naturaleza con Alfonso X, que, "frente a la rotunda carnalidad de la escultura pastoral de la

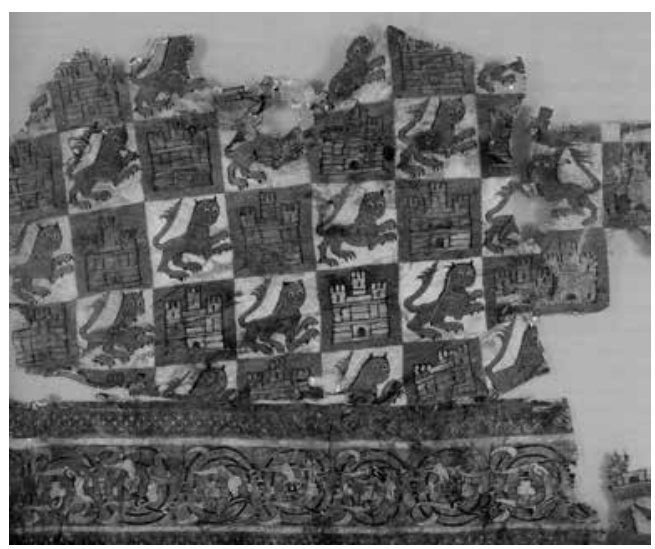

Fig. 3. Fragmento del manto de Fernando III en la Real Armería de Madrid (foto: Vestiduras ricas. El monasterio de las Huelgas y su época 1170-1340 (catálogo de exposición), Patrimonio Nacional, Madrid, 2005, p. 93). 
iglesia regular, ofrece soluciones visuales emparentadas con esquemas decorativos propios del arte andalusí" ${ }^{58}$, trasladando a otros medios sus principios estéticos de reiteración y de abigarramiento, y que, aparte de conferir una especial personalidad al arte castellano de los siglos XIII y XIV, imprime su sello distintivo al sistema heráldico de estos territorios ${ }^{59}$. Se escoge para los sepulcros reales en detrimento de opciones quizás más vistosas por su mayor despliegue figurativo.

La cubierta del sepulcro de la infanta doña Leonor debió de ser la típica cubierta a doble vertiente o en albardilla característica de tantos sepulcros contemporáneos del monasterio cisterciense de Santa María la Real de las Huelgas de Burgos, empezando por el de su hermano el infante don Fernando de la Cerda. Todo él estaría cubierto por una trama de cuarteles con las señales de Castilla y de León (hasta setenta y dos, si atendemos al testimonio de De las Cosigas) ${ }^{60}$, de los cuales apenas subsisten hoy cuatro cuarteles, de los cuales se encuentran en un estado de mínima integridad únicamente dos cuarteles (los dos primeros) ${ }^{61}$. Por debajo de los tres primeros cuarteles queda una mínima franja de un orden inferior de cuarteles, dispuestos, como era de esperar, a tresbolillo. Los muebles heráldicos presentan un diseño cuidado que responde a la evolución operada a lo largo del tercer cuarto del siglo XIII, encontrándose cerca, sin que quepa hablar de identidad, de los del sepulcro del infante don Fernando de la Cerda. Los leones caleroganos (Fig. 4) tienen todavía la cabeza me-

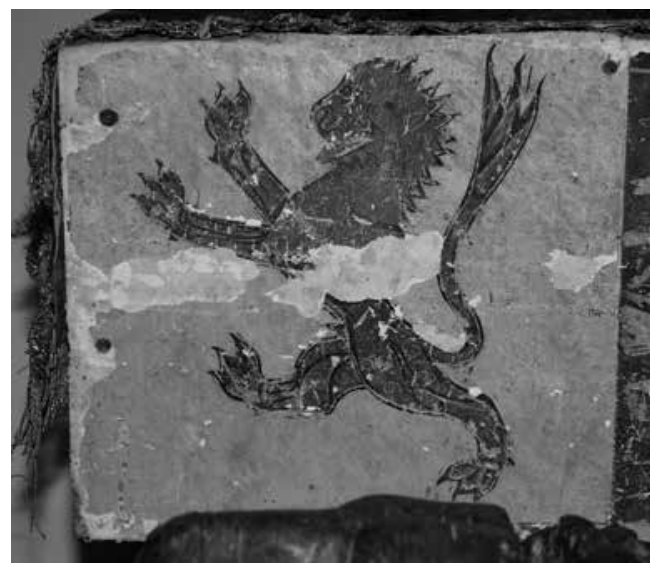

Fig. 4. Detalle del sepulcro de la infanta doña Leonor en el Real Monasterio de Santo Domingo de Caleruega. Estado en 2013. dio vuelta hacia el espectador (modelo primitivo que se contrapone al modelo maduro, en el que los leones tienen la cabeza de perfil, que, sin embargo, perduró en el tiempo) y, sobre todo, su cola acusa aún la falta de flexibilidad propia de los modelos antiguos. Los castillos (Fig. 5) llaman la atención por su intensidad cromática, testimonio de la riqueza que debió de caracterizar a esta obra a pesar de su aparente sencillez.

Si bien en el fragmento que ha llegado hasta nuestros días el cuartel que aparece en primer lugar es el de León, su disposición, mirando a la diestra, indica, claramente, que nos encontramos ante una representación convencional de las armas reales plenas, con Castilla precediendo a León. No debieron de existir, pues, armas específicamente concebidas para doña Leonor, pues la costumbre de diferenciar las armas para los infantes, aun cuando estos fueran de corta edad, iniciada con la descendencia de Fernando III, no parece que se hiciera extensiva a las mujeres, que habían de adoptar las armas de sus maridos incorporando en posición secundaria las armas reales ${ }^{62}$. Si el sepulcro de la infanta doña Constanza, hermana de la infanta doña Leonor, en el monasterio cisterciense de Santa María la Real de las Huelgas de Burgos hubiese conservado algún testimonio heráldico, bien fuese en su decoración, bien fuese en su ajuar, tendríamos más argumentos a propósito de esta cuestión ${ }^{63}$.

Como se habrá podido comprobar a lo largo de los párrafos precedentes, las Huelgas son

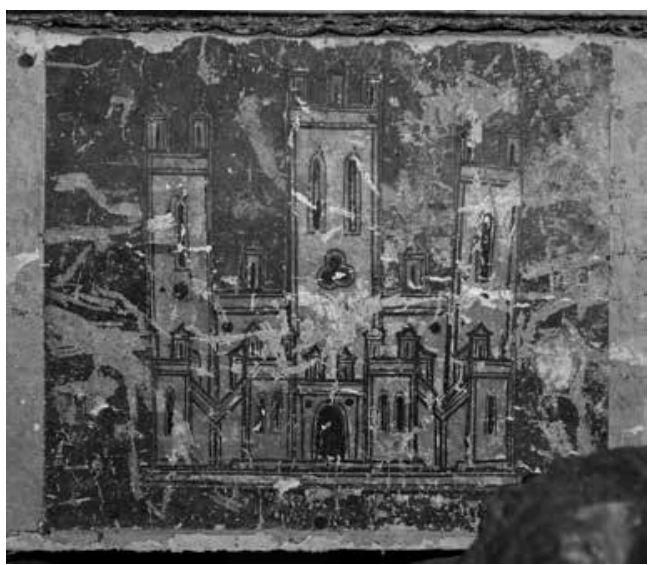

Fig. 5. Detalle del sepulcro de la infanta doña Leonor en el Real Monasterio de Santo Domingo de Caleruega. Estado en 2013. 
un término de comparación constante para el sepulcro calerogano que aquí nos ocupa. Ciertamente, el sepulcro de la infanta doña Leonor pertenece plenamente pese a su distinta ubicación, a la familia de los sepulcros reales del cenobio burgalés ${ }^{64}$. Su principal diferencia radica en los materiales empleados para su fabricación: madera policromada en lugar de piedra policromada (quizás porque el empleo de materiales lígneos facilitaba su transporte desde el lugar de su fabricación, que no pudo ser otro que Burgos). De esta manera, el sepulcro de la infanta doña Leonor entronca, asimismo, con toda una tradición de sepulcros burgaleses de madera policromada cuyos mejores ejemplos, estudiados por Ruiz Maldonado, datan ya del siglo XIV ${ }^{65}$, si bien esta tradición cuenta con sólidas raíces en el siglo XIII (entre sus primeras manifestaciones quizás el ejemplo más destacado sea el desmantelado sepulcro de don Sancho Sánchez CarriIlo, procedente de la ermita de San Andrés de Mahamud, de ca. 1295, cuya imagen yacente se conserva en The Cincinnati Art Museum y cuyas tablas laterales, con pinturas sobre pergamino aplicado a la madera, se conservan en el Museu Nacional d'Art de Catalunya ${ }^{66}$. Sin embargo, el sepulcro de la infanta doña Leonor adapta esta tradición a las exigencias de la estética cortesana anteriormente enunciada, renunciando a la figuración y al bulto y apostando, a cambio, por la transposición pictórica de patrones textiles de inspiración andalusí. Por otra parte, el sepulcro de la infanta doña Leonor insiste en lo que parecen rasgos distintivos de la pintura gótica burgalesa del siglo XIII: extraordinario afán de integración de las artes (que requiere siempre su estudio en combinación con otras especialidades artísticas), unido a un profundo casticismo de sus modelos ornamentales ${ }^{67}$. Con este trasfondo resulta inevitable dejar de mencionar a Juan Gon- zález, el pintor de las imágenes de Burgos, exhumado por la sorprendente aparición en 2009 en Christie's de Londres del contrato del sepulcro de doña Mayor Guillén de Guzmán, datado en $1276^{68}$. Este contrato nos pone ante un pintor contemporáneo que, por la manera antonomástica en que aparece mencionado, cuenta, indudablemente, con prestigio, el cual trabaja para el entorno de la familia real (doña Mayor Guillén de Guzmán, en tanto que amante de Alfonso X, era la madre de doña Beatriz, reina de Portugal por su matrimonio con Alfonso III, y el sepulcro es contratado por don Juan Pérez, capellán de la reina doña Beatriz), realizando, como se detalla minuciosamente en el contrato, un sepulcro de madera policromada (escultórico, fundamentalmente). Ubicación (espacial y temporal), perfil y competencias hacen de Juan González un buen candidato para haber fabricado el sepulcro de la infanta doña Leonor, pero lo poco conservado de este y lo menos aún de su única obra documentada, destinada al convento de clarisas de Alcocer, de donde la estatua yacente, único elemento que llegó al siglo XX, desapareció durante la guerra civil, hacen imposible avanzar en esta hipótesis ${ }^{69}$.

En cualquier caso, el sepulcro de la infanta doña Leonor en el Real Monasterio de Santo Domingo de Caleruega se nos ofrece, pese a su pobre condición, como un testimonio importante del arte de la era alfonsí, en tanto que índice de su compromiso con la creación de un convento de religiosas de la orden dominicana en Caleruega a mayor gloria del santo, de la orden y de Castilla y en tanto que ejemplo de una estética cortesana en la que las telas, la heráldica y la tradición andalusí jugaron un papel determinante para crear un ambiente de extrema originalidad en la Europa del siglo XIII. 


\section{NOTAS}

* Este artículo se enmarca en el proyecto de investigación Cultura visual y cultura libraria en la Corona de Castilla (1284-1350) III, financiado por el Ministerio de Economía y Competitividad (referencia HAR2012-34876). La labor bibliográfica pudo ser completada merced a una ayuda del plan de movilidad de personal investigador de la Universidad de Valladolid, cofinanciada por el Banco de Santander, de la que disfruté en 2013 en calidad de Visiting Fellow en el Index of Christian Art (Department of Art and Archaeology) de la Princeton University. Este artículo no hubiera sido posible sin la hospitalidad y sin la generosidad de los monjes benedictinos de Santo Domingo de Silos, de los frailes dominicos de Caleruega $y$, muy especialmente, de las religiosas del Real Monasterio de Santo Domingo de Caleruega. Dedico este trabajo a mi amiga Irene Peña Peña, calerogana.

${ }^{1}$ Crónica de Alfonso X (M. González Jiménez, Ed.), Real Academia Alfonso X el Sabio, Murcia, 1999, p. 11.

${ }^{2}$ A. Ballesteros Beretta, Alfonso $X$ el Sabio, Academia Alfonso $X$ el Sabio y Salvat Editores, Barcelona, 1963, pp. 541-544. La boda formaba parte de la política imperial de Alfonso X. En contradicción con lo anteriormente dicho, la Crónica de Alfonso $X$ presenta correctamente en dos ocasiones a Guillermo VII como marido de la infanta doña Beatriz, v. Crónica..., o. cit., pp. 50 y 212, si bien la primera referencia, correspondiente a 1269, es parcialmente errónea en la medida en que el matrimonio no se celebró hasta 1271.

${ }^{3}$ Marqués de Mondéjar, Memorias históricas del rei don Alonso el Sabio i observaciones a su chrónica, Joaquín Ibarra, Madrid, 1777, pp. 539-540.

${ }^{4}$ Crónica..., o. cit., pp. 224-225. La boda fue promovida por su hermano el infante don Sancho, en rebeldía contra su padre, para afianzamiento de sus apoyos.

${ }^{5}$ A. Ballesteros Beretta, o. cit., p. 548. Las referencias en J. Torres Fontes, Repartimiento de Murcia, Consejo Superior de Investigaciones Científicas y Academia Alfonso X el Sabio, Murcia, 1960, pp. 103, 187, 190, 192 у 212.
${ }^{6}$ A. Ballesteros Beretta, o. cit., p. 543.

7 M. González Jiménez, Alfonso $X$ el Sabio, Editorial Ariel, Barcelona, 2004, p. 126. Los Anales Silenses a que a continuación me referiré sitúan su nacimiento en 1257.

8 B. Desclot, Crònica, (M. Coll i Alentorn, Ed.), vol. III, Editorial Barcino, Barcelona, 1949, p. 12.

${ }_{9}^{9}$ A. C. Floriano, "Anales Toledanos III", Cuadernos de Historia de España, núms. XLIII-XLIV, 1967, p. 173.

10 M. González Jiménez, "Unos anales del reinado de Alfonso X", Boletín de la Real Academia de la Historia, t. CXCII, 1995, p. 477.

11 Sobre la "ida al imperio", v. M. González Jiménez, Alfonso X..., o. cit., pp. 272-293.

${ }^{12}$ A. Ballesteros Beretta, o. cit., p. 772.

${ }^{13}$ Fr. A. G. Peláez, O. P., Cuna y abolengo de Santo Domingo de Guzmán. Estudio histórico de Caleruega, Imprenta de Cándido Alonso y C. ${ }^{a}$, Madrid, 1917, p. 271; Fr. E. Martínez, O.P., Colección diplomática del Real Convento de Santo Domingo de Caleruega, Editorial "El Santísimo Rosario", Vergara, 1931, p. Ixi. Modernamente se han ocupado de este sepulcro D. Iturgaiz Ciriza, Caleruega, primer lugar dominicano. Guía artístico-documental, Editorial San Esteban, Salamanca, 1989, p. 49; Sor C. González González, O.P., Real Monasterio de Santo Domingo de Caleruega. Fundación de Alfonso $X$ el Sabio, Editorial San Esteban, Salamanca, 1993, pp. 96 y 313; J. E. Martín Lozano y J. M. Vicente Pradas, Real Monasterio de Caleruega. Cuna de Santo Domingo de Guzmán, Edilesa, Trobajo del Camino, 2007, p. 54 (donde publican una buena fotografía en color); J. A. Casillas García, Caleruega. La villa afortunada, s. e., Burgos, 2009, pp. 349-350, lám. 30.3. Destaca, especialmente, el caudal de información aportado por sor Carmen González González.

14 En 1320 don Juan el Tuerto, hijo del infante don Juan (hermano de la infanta doña Leonor), tomó bajo su protección el convento de Caleruega por onrra dela infanta donna Leonor mi tia que yaze y enterrada, que dios perdone, v. Fr. E. Martínez, o. cit., pp. 87-88 (núm. LXXVIII). En 1326 don Fernando Díaz de Haro, hijo de la infanta doña Violante (hermana de la infanta doña Leonor), tomó bajo su protección el convento de Caleruega por honra de la Infanta doña Leonor mi tia, que yaze y enterrada, v. idem, p. 103 (núm. LXXXIV). Un tercer testimonio de 1331 aducido por Fr. E. Martínez, v. idem, pp. 105-106 (núm. LXXXVI), no responde a un documento antiguo original, sino a una cita del erudito del siglo XVII José Pellicer.

15 R. del Arco, Sepulcros de la casa real de Castilla, Consejo Superior de Investigaciones Científicas, Madrid, 1954, pp. 259-260. Sobre las gestiones académicas de principios del siglo XIX, que concluyeron que no existían pruebas suficientes para atribuir el sepulcro zaragozano a la infanta doña Leonor, v. J. Maier Allende, "Aragón" en 250 años de arqueología y patrimonio. Documentación sobre arqueología y patrimonio histórico de la Real Academia de la Historia. Estudio general e índices (M. Almagro-Gorbea y J. Maier Allende, Eds.), Real Academia de la Historia, Madrid, 2003, pp. 136-137.

${ }^{16}$ Sor C. González González, o. cit.

17 R. Ríos de la Llave, Mujeres de clausura en la Castilla medieval: el Monasterio de Santo Domingo de Caleruega, Universidad de Alcalá, Alcalá de Henares, 2007.

18 D. Iturgaiz Ciriza, o. cit.; J. E. Martín Lozano y J. M. Vicente Pradas, o. cit.

19 Sor C. González González, o. cit., p. 101; R. Ríos de la Llave, o. cit., p. 153. Lo cuenta el Cerratense en su vida de Santo Domingo de Guzmán: Cum auditum esset in Hyspania quod canonizatus esset beatus Dominicus, frater Mames, germanus ipsius, uenit Calerogam et predicans populo induxit eos ut in loco illo ubi natus fuerat beatus Dominicus ecclesiam hedificarent, v. F. Villamil Fernández, Vitas Sanctorum. Rodrigo de Cerrato. Estudio y edición, Tesis Doctoral, Universidade de Santiago de Compostela, 1991, p. 528. La existencia de esta iglesia está confirmada por un privilegio rodado de Fernando III de 31 de octubre de 1237. En 1297, según manifiesta una bula del 
patriarca de Constantinopla, se estaba acometiendo su renovación, v. Sor C. González González, o. cit., pp. 101104; R. Ríos de la Llave, o. cit., p. 161. Esta iglesia fue completamente reconstruida a finales del siglo XVI, incorporándose entonces al vecino convento, v. infra n. 25.

20 Sor C. González González, o. cit, pp. 23-56; R. Ríos de la Llave, o. cit., pp. 55-128.

${ }^{21}$ Sor C. González González, 0. cit, pp. 62-74; R. Ríos de la Llave, o. cit., pp. 149-161 y 169-172. Los documentos en Fr. E. Martínez, o. cit., pp. 8-13 (núms. VIIIX), 15-18 (núm. XIII) y 34 (núm. XXVIII).

${ }^{22}$ R. Ríos de la Llave, o. cit., p. 152. Hasta entonces las monjas debieron de emplear la iglesia de Santo Domingo construida en 1234 a instancias del Beato Manés de Guzmán, según se deduce del documento de 1270 y de lo que era más habitual en el proceso cronoconstructivo de los monasterios medievales (a saber, construcción de una iglesia provisional o aprovechamiento, con esta finalidad, de una iglesia preexistente en tanto se consolidaba la comunidad y se edificaba la iglesia conventual). No podemos compartir, pues, la opinión de idem, p. 155, que piensa que en 1270 ya se hizo entrega a la comunidad de la nueva iglesia (dedicada, como veremos, a Santa María), aún inconclusa, la cual coexistió con la vieja iglesia de Santo Domingo durante toda la Edad Media.

${ }^{23}$ F. Villamil Fernández, o. cit., p. 529.

${ }^{24}$ He de destacar, no obstante, que la heráldica que lucen las claves de las cuatro bóvedas de crucería conservadas no pertenece a la casa real. Sus armas (cuartelado: primero, lis; segundo, puy flordelisado -el orden de los cuarteles se va alternando en las sucesivas bóvedas-) se corresponden con las que, según el conocido Libro de la cofradía de Santiago, empleaba el linaje burgalés de Giralte (cuartelado: primero, de oro, lis de gules; segundo, de azur, puy flordelisado de oro), v. F. Menéndez Pidal de Navascués, Caballería medieval burgalesa. El libro de la cofradía de Santiago, Universidad de Cádiz y Universidad de Burgos, Madrid, 1996, pp. 72 (núm. 26, f. 24r, Simón Pérez Giralte), 73, (núm. 57, f. 28r, Juan del Puche), 74 (núm. 85, f. 31v, Juan Giralte) y 76 (núm. 151, f. 39v, Juan Giralte el Mozo), siendo llamativo el empleo del puy flordelisado, característico de la heráldica catalana, de donde sería originario este linaje, v. idem, pp. 41-42. Una priora de nombre doña Petronila Giralte figura al frente de la comunidad de Caleruega entre 1351 y 1353 y entre 1369 y 1381, v. R. Ríos de la Llave, o. cit., pp. 175 y 178.

${ }^{25}$ Sor C. González González, 0. cit., pp. 182-184.

${ }^{26}$ S. Aguadé Nieto, "Alfonso $X$ el Sabio y las órdenes mendicantes" en Könige, Landesherren und Bettelorden: Konflikt und Kooperation in West- und Mitteleuropa bis zur Frühen Neuzeit (D. Berg, Ed.), Dietrich-Coelde-Verlag, Werl, 1998, pp. 288-292. VIII)

${ }^{27}$ Fr. E. Martínez, o. cit., p. 9 (núm.

28 Sor C. González González, o. cit., pp. 89-90, llama la atención sobre el hecho de que Alfonso $X$ nunca se refiriera a una eventual finalidad funeraria de su fundación.

${ }^{29}$ A finales de 2013 el sepulcro ha ingresado en el Centro de Conservación y Restauración de Bienes Culturales de Castilla y León para su restauración.

${ }^{30}$ Sus dimensiones son $25,5 \mathrm{~cm}$ de altura, $110 \mathrm{~cm}$ de anchura y $32,5 \mathrm{~cm}$ de profundidad.

${ }^{31}$ La colocación de estos leones, de entre 85 y $95 \mathrm{~cm}$ de profundidad, ha variado con el paso del tiempo: los de los extremos miran, en la actualidad, hacia el exterior, pero en la foto que publica Sor C. González González, o. cit., p. 92, miran hacia el interior, disposición esta que, a la vista de ejemplos contemporáneos (especialmente, a la vista de los sepulcros representados en los sepulcros de los obispos don Pedro Rodríguez Quijada y don Gonzalo de Hinojosa en la catedral de Burgos), debió de ser la original. Su tamaño y número invitan a pensar en las notables dimensiones del sepulcro original.

32 Sor C. González González, o. cit., pp. 229-231. Se conserva en el archivo del monasterio con la signatura caj. 12, 57 (306).
${ }^{33}$ Fr. E. Martínez, O. cit., p. |xi. El P. Martínez desmiente esta atribución basándose en los lujosos vestidos de la persona enterrada en este sepulcro, pues doña Margarita de la Cerda, en tanto que monja, tendría que haber sido enterrada con el hábito de la orden. La atribución del sepulcro a esta señora también podría desmentirse a partir de la heráldica, pues en ningún caso le correspondería el empleo exclusivo de las armas reales plenas, sino el empleo de las armas de su padre (cuartelado: primero, de Castilla; segundo y tercero, de Francia antiguo; cuarto, de León), v. F. Menéndez Pidal, Heráldica de la casa real de León y de Castilla (siglos XII-XVI), Ediciones Hidalguía, Madrid, 2011, p. 180.

${ }^{34}$ Abadía de Silos, ms. 168 (olim 98), bifolio 32, ff. 1r-1v. El autor desmiente de esta manera que el sepulcro corresponda, como quieren algunos, a la infanta doña Blanca de Portugal (hija de la reina de Portugal doña Beatriz -nieta, por tanto, por vía natural, de Alfonso $X$ el Sabio-), bienhechora del convento, cuyo cuerpo, como es bien sabido, reposa en el monasterio cisterciense de Santa María la Real de las Huelgas de Burgos. El manuscrito es una recopilación de noticias sobre Santo Domingo de Guzmán y sobre el Real Monasterio de Santo Domingo de Caleruega que tiene como sección más destacada la titulada Fundación del Real Convento de religiosas de Santo Domingo de Guzmán de esta villa de Caleruega, sus privilegios, donaciones y regalías que goza desde el año de 1266 que le fundó y dotó el rey don Alonso el Sabio hasta el año presente de 1756 (sic). J.M.J. año 1757, que incluye esta referencia.

35 Sor C. González González, o. cit., pp. 242-243.

${ }^{36}$ Sobre el especial valor del coro como lugar de enterramiento, v. I. G. Bango Torviso, "El espacio para enterramientos privilegiados en la arquitectura medieval española", Anuario del Departamento de Historia y Teoría del Arte, vol. IV, 1992, pp. 119-120.

${ }^{37}$ Es cuestión no aclarada el lugar de enterramiento de la primogénita $y$, durante un tiempo, heredera de Alfonso $X$, a la que se señalan enterramien- 
tos cuando menos en el convento de Santa Clara de Toro y en el convento de Santo Domingo el Real de Madrid, v. R. del Arco, o. cit., pp. 252-253. El sepulcro toresano, que tiene visos de verosimilitud, se encontraba originalmente en el coro, v. J. Navarro Talegón, Catálogo monumental de Toro y su alfoz, Caja de Ahorros Provincial de Zamora, Valladolid, 1980, p. 226, fot. 293.

${ }^{38}$ R. Sánchez Ameijeiras, "Crisis, ¿qué crisis? Sobre la escultura castellana de la primera mitad del siglo XIV" en El Trecento en obres. Art de Catalunya $i$ art d'Europa al segle XIV (R. Alcoy, Ed.), Universitat de Barcelona, Barcelona, 2009, pp. 257-272; R. Alonso Álvarez, "La memoria de Alfonso VIII de Castilla en las Huelgas de Burgos: arquitectura y liturgia funeraria", en 1212, un año, un reinado, un tiempo de despegue (E. López Ojeda, Coor.), Instituto de Estudios Riojanos, Logroño, 2013, pp. 367-376.

${ }^{39}$ Fr. A. G. Peláez, I. cit.; Fr. E. Martínez, o. cit., p. Ixi.

40 Sor C. González González, o. cit., p. 246.

${ }^{41}$ Idem, p. 313.

42 Fr. A. G. Peláez, I. cit.

${ }^{43}$ Sor C. González González, I. cit. Fr. E. Martínez, I. cit., menciona, asimismo, que se conservan "pedazos de seda en que estuvo envuelto el cuerpo".

44 Sor C. González González, I. cit. donde recoge los recuerdos de dos religiosas que presenciaron estos hechos. La nueva urna, "menos de la cuarta parte" de la original, la fabricó un carpintero aficionado del pueblo llamado Florentino, discapacitado, al que se había cedido por caridad un espacio en la vicaría del convento para que estableciese allí su taller.

45 Idem, p. 96, donde justifica el traslado "a causa del mal estado en que se encontraba la urna sepulcral". El acta del traslado se conserva en el archivo del monasterio con la signatura carp. 70, 59.

${ }^{46} \mathrm{Ibidem}$.

47 F. Gutiérrez Baños, "Pintura monumental en tiempos del Códice Rico de las Cantigas de Santa María" en Alfonso X el Sabio 1221-1284. Las Cantigas de Santa María. Códice Rico, ms. T-1-1. Real Biblioteca del monasterio de San Lorenzo de El Escorial (L. Fernández Fernández y J. C. Ruiz Souza, Dirs.), Testimonio Compañía Editorial, Madrid, 2011, vol. II, pp. 381-386.

${ }^{48}$ Alfonso $X$ no fue a Burgos hasta 1276, pero pasó allí casi todo el año 1277 (hasta el 17 de febrero de 1278), v. M. González Jiménez y M. A. Carmona Ruiz, Documentación e itinerario de Alfonso $X$ el Sabio, Universidad de Sevilla, Sevilla, 2012, pp. 79-81.

${ }^{49}$ Sobre el monasterio de las Huelgas, v. Vestiduras ricas. El monasterio de las Huelgas y su época 1170-1340 (catálogo de exposición), Patrimonio Nacional, Madrid, 2005. Sobre el sepulcro del infante don Fernando de la Cerda, v. M. J. Gómez Bárcena, Escultura gótica funeraria en Burgos, Diputación Provincial de Burgos, Madrid, 1988, pp. 198-199, con especial énfasis en su dimensión escultórica, y F. Gutiérrez Baños, Aportación al estudio de la pintura de estilo gótico lineal en Castilla y León: precisiones cronológicas y corpus de pintura mural y sobre tabla, Fundación Universitaria Española, Madrid, 2005, t. II, pp. 73-74 (núm. 16), con especial énfasis en su dimensión pictórica. Este sepulcro es más monumental por su disposición en un arco con complemento escultórico.

50 O. Pérez Monzón, "Heráldica versus imagen" en Alfonso X el Sabio (catálogo de exposición), Región de Murcia, Ayuntamiento de Murcia y Caja Mediterráneo, Murcia, 2009, pp. 94-101.

51 F. Español Bertrán, "Los indumentos del cuerpo a la espera del Juicio Final" en Vestiduras..., o. cit., pp. 81-84.

52 G. Menéndez Pidal, La España del siglo XIII leída en imágenes, Real Academia de la Historia, Madrid, 1987, pp. 37 y 52.

${ }^{53}$ C. Herrero, "27.- Fragmento del manto de Fernando III" en Metropolis totius Hispaniae (catálogo de exposición), Ayuntamiento de Sevilla y Cabildo Metropolitano de Sevilla, Sevilla, 1998, pp. 238-239.

${ }^{54}$ F. Gutiérrez Baños, "La pintura en el territorio burgalés en los siglos XIII y XIV: el desarrollo del estilo gótico lineal" en El arte gótico en el territorio burgalés (E. J. Rodríguez Pajares, Dir.), Universidad Popular para la Educación y Cultura de Burgos, Burgos, 2006, pp. 275-278, fig. 1.

${ }^{55}$ F. J. Hernández, "Two Weddings and a Funeral: Alfonso X's Monuments in Burgos", Hispanic Research Journal, vol. 13, núm. 5, 2012, pp. 412-417 y 421-422, fig. 3.

${ }^{56}$ T. Laguna Paúl, "Mobiliario medieval de la capilla de los Reyes de la catedral de Sevilla. Aportaciones a los "ornamenta ecclesiae" de su etapa fundacional", Laboratorio de Arte, núm. 25, 2013, pp. 69-70, figs. 2, 4, 5,8 y 9 .

${ }^{57}$ F. Gutiérrez Baños et alii, "Restauración virtual de las pinturas murales de la ermita de San Andrés de Mahamud: un conjunto funerario castellano de finales del siglo XIII", en VI Congreso Internacional Restaurar la Memoria. La gestión del patrimonio hacia un planteamiento sostenible, Valladolid, 31 de octubre-1-2 de noviembre de 2008. Junta de Castilla y León, Salamanca, 2010, t. II, pp. 595-602.

${ }^{58}$ R. Sánchez Ameijeiras, o. cit., p. 257. V., asimismo, G. Palomo Fernández y J. C. Ruiz Souza, "Nuevas hipótesis sobre las Huelgas de Burgos. Escenografía funeraria de Alfonso X para un proyecto inacabado de Alfonso VIII y Leonor Plantagenêt", Goya, núms. 316-317, 2007, pp. 35-37.

${ }^{59}$ F. Menéndez Pidal de Navascués, Los emblemas heráldicos. Una interpretación histórica, Real Academia de la Historia, Madrid, 1993, pp. 82-90.

${ }^{60}$ A la vista de las dimensiones de los cuarteles conservados (en torno a $25 \times 27,5 \mathrm{~cm}$ cada uno de ellos), no es difícil imaginar que el sepulcro tuviese una longitud equivalente a ocho cuarteles, esto es, a $220 \mathrm{~cm}$, comparable a la de otros sepulcros del periodo.

61 Sor C. González González, o. cit., p. 313, cuenta que "En nuestros días, una mano inexperta, desconociendo lo que contenía, la golpeó fuertemente para abrirla, sin conseguirlo. Las deplorables consecuencias afectaron a las escasas pinturas que le quedaban". La foto que publica esta autora muestra un mayor estado de integridad para el león del primer cuartel, v. idem, p. 92. 
${ }^{62}$ F. Menéndez Pidal, Heráldica..., o. cit., pp. 122-123. Solo de la infanta doña Berenguela, señora de las Huelgas, hija de Fernando III, se conserva un sello en el que las armas reales aparecen rodeadas por cuatro castillos y por cuatro águilas en alternancia, como si se tratase de una bordura a manera de brisura.

${ }^{63}$ M. Gómez-Moreno, El panteón real de las Huelgas de Burgos, Consejo Superior de Investigaciones Científicas, Madrid, 1946, pp. 38-39, 72 y 102. Don Manuel cree a esta señora hija ilegítima de Alfonso X. Sin embargo, los Anales Silenses la identifican como infanta, situando su muerte en 1282 , v. M. González Jiménez, "Unos anales...", o. cit., p. 480 (§ 13).

${ }^{64}$ M. J. Gómez Bárcena, o. cit., pp. 187-201.

${ }^{65}$ M. Ruiz Maldonado, "Escultura funeraria en Burgos: los sepulcros de los Rojas, Celada y su círculo", Boletín del Museo e Instituto "Camón Aznar", núm. LVI, 1994, pp. 45-126.

${ }^{66}$ F. Gutiérrez Baños, Aportación...., o. cit., t. II, pp. 101-109 (núm. 32).

${ }^{67}$ F. Gutiérrez Baños "La pintura en el territorio burgalés...", o. cit., p. 274.

68 J. L. García de Paz, Patrimonio desaparecido de Guadalajara, $2^{\text {a }}$ ed., AACHE Ediciones, Guadalajara, 2011, pp. 139-140. El documento, del que se tienen noticias desde el siglo XVII, se vendió por 10.000 libras esterlinas, v. http://www.christies.com/lotfinder/ books-manuscripts/contract-for-thetomb-of-dona-mayor-5267930-details. aspx [Consulta: 23/07/2013].

${ }^{69} \mathrm{La}$ imagen yacente de doña Mayor Guillén de Guzmán llegó a ser estudiada por R. de Orueta, La escultura funeraria en España. Provincias de Ciudad Real, Cuenca, Guadalajara, Centro de Estudios Históricos, Madrid, 1919, pp. 5-21 (nueva ed., AACHE Ediciones, Guadalajara, 2000, pp. 15-27). Sobre su desaparición, v. J. L. García de Paz, o. cit., pp. 132-134. 